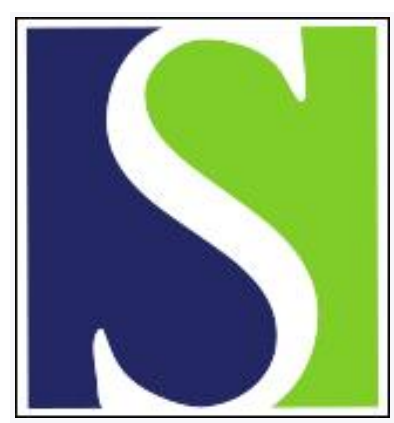

Scand J Work Environ Health 1987;13(2):100-107

https://doi.org/10.5271/sjweh.2074

Issue date: Apr 1987

Mortality among workers at a uranium processing facility, the Linde Air Products Company Ceramics Plant, 1943-1949.

by Dupree EA, Cragle DL, McLain RW, Crawford-Brown DJ, Teta MJ

This article in PubMed: www.ncbi.nlm.nih.gov/pubmed/3602963

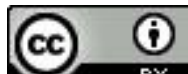




\title{
Mortality among workers at a uranium processing facility, the Linde Air Products Company Ceramics Plant, 1943-1949
}

\author{
by Elizabeth A Dupree, ScM ${ }^{1}$, Donna L Cragle, $\mathrm{PhD}^{1}$, Richard W McLain, MSPH${ }^{1}$, \\ Douglas $\mathrm{J}$ Crawford-Brown, $\mathrm{PhD}^{2}, \mathrm{M}$ Jane Teta, $\mathrm{MPH}^{3}$
}

\begin{abstract}
DUPREE EA, CRAGLE DL, MC LAIN RW, CRAWFORD-BROWN DJ, TETA MJ. Mortality among workers at a uranium processing facility, the Linde Air Products Company Ceramics Plant, 1943-1949. Scand J Work Environ Health 13 (1987) 100-107. A retrospective cohort mortality study of 995 white males employed more than $30 \mathrm{~d}$ at a uranium processing facility in upstate New York between 1943 and 1949 investigated the association between excess observed deaths and long-term occupational exposure via inhalation to uranium compounds. Two comparison groups were used, the white male population of the United States and the white male population in the New York counties of Erie and Niagara. The vital status determination was $94.3 \%$ complete through 31 December 1979 . With the use of the national comparison group, statistically significantly increased standardized mortality ratio (SMR) values were observed for all causes (SMR 118), laryngeal cancer (SMR 447), all circulatory diseases (SMR 118), arteriosclerotic heart disease (SMR 119), all respiratory diseases (SMR 152), and pneumonia (SMR 217). Sitespecific outcomes of special interest with a statistically increased number of deaths above expected were laryngeal cancer (observed 5) and pneumonia (observed 17). No association was found with length of employment or work in the most hazardous areas of the plant. The comparison with regional rates gave similar results.
\end{abstract}

Key terms: external radiation, internal radiation, laryngeal cancer, pneumonia, respiratory disease.

A large body of literature exists concerning the health effects of radiation on human populations (2). Most of this information deals with exposure to relatively high doses of ionizing radiation from either internal or external sources. There is little doubt that radiation exposure at high levels increases the risk of cancer at those sites that are heavily irradiated $(1,8,9,12,17$, 19). However, there is much controversy concerning the carcinogenic effects of low-level long-term irradiation. Efforts have been made to extrapolate to risks at low levels from those determined at high levels. This approach ignores the fact that exposures at high levels are generally of relatively short duration, whereas those at low levels are usually protracted. So the question remains unanswered as to the effect of low-level exposure to ionizing radiation over longer durations (2).

One of the problems encountered in studying lowlevel exposure effects is the lack of a population large enough to quantitate reliably any effects that are found. Therefore, consistency of results from studies

1 Center for Epidemiologic Research, Oak Ridge Associated Universities, Oak Ridge, Tennessee 37831, United States.

2 Department of Environmental Science and Engineering, University of North Carolina, Chapel Hill, North Carolina 27514, United States.

3 Corporate Health, Safety and Environmental Affairs, Union Carbide Corporation, Danbury, Connecticut 06817, United States.

Reprint requests to: Ms EA Dupree, Center for Epidemiologic Research, Oak Ridge Associated Universities, PO Box 117, Oak Ridge, TN 37831-0117, USA. of populations with similar exposures becomes important. In studies of the effects of low-level exposures to internal alpha radiation, cohorts of uranium-processing workers are an important type of population group to consider. However, one problem in studying persons exposed to uranium is the difficulty of separating the radiologic effects of uranium from its chemical effects. A few studies of these workers appear in the literature. Among uranium millers, no increased overall cancer risk has been found $(23,24)$. In a study of a cohort of uranium-processing workers, mortality due to cancer of the lung was found to be increased, although not significant statistically (15). In a subsequent nested case-referent study of lung cancer in the population, an observed statistically significant increased risk was confined to workers who were first exposed to uranium after 44 years of age and who had received a cumulative lung dose of $200 \mathrm{mGy}$ or more (3).

The purpose of the present retrospective cohort mortality study was to investigate the relationship between exposure to low-level ionizing radiation and subsequent health outcomes among workers at the Linde Air Products Company Ceramics Plant. This paper addresses that issue by evaluating the mortality in this worker cohort.

\section{Subjects and methods}

Located in Buffalo, New York, this uranium processing plant was in operation from 1943 to 1949 . Belgian 
Congo pitchblende and domestic uranium (U) ores were converted to uranium tetrafluoride $\left(\mathrm{UF}_{4}\right)$. Intermediate products in the uranium processing operations were uranium oxide $\left(\mathrm{U}_{3} \mathrm{O}_{8}\right)$, uranium trioxide $\left(\mathrm{UO}_{3}\right)$, and uranium dioxide $\left(\mathrm{UO}_{2}\right)$, which are relatively physiologically insoluble in comparison to uranium hexafluoride $\left(\mathrm{UF}_{6}\right)$. In addition, for a short time, nickel (Ni) metal was converted to nickel powder, and experimental work was done on the conversion of uranium hexafluoride to uranium trioxide. In contrast to the uranium ore processing operations, the conversion of uranium hexafluoride involved exposure to more soluble uranium compounds. Because of the period and circumstances (World War II) of operation, the industrial hygiene and health physics standards of the plant were less stringent than those in effect today.

Workers at the Linde facility had a potential for exposure to ionizing radiation and to a wide variety of chemicals. Nine of the chemicals were evaluated as potential hazards at the plant, namely, chlorine $\left(\mathrm{Cl}_{2}\right)$, hydrofluoric acid (HF), lead sulfate $\left(\mathrm{PbSO}_{4}\right)$, nickel (Ni), nitric acid and nitrogen oxides $\left(\mathrm{HNO}_{3}, \mathrm{NO}_{\mathrm{x}}\right)$, silicon dioxide $\left(\mathrm{SiO}_{2}\right)$, sulfuric acid $\left(\mathrm{H}_{2} \mathrm{SO}_{4}\right)$, uranium dust, and uranium hexafluoride. Among these chemicals, only sulfuric acid is a suspect carcinogen (20). Although some nickel compounds have been associated with increased cancer risk (5), there are no data, thus far, to suggest that the metallic or powdered forms of nickel used at this plant are carcinogenic (4). Adverse nonmalignant respiratory effects have been associated with chronic exposure to nitric acid, sulfuric acid, and silicon dioxide (14).

Uranium was both a chemical and a radiation hazard. The chemical hazard arose from inhalation and ingestion of uranium dust and its subsequent metabolism in the body. The radiation hazards were both external and internal. The internal hazard was from alpha radiation emitted through the decay of uranium and radon $(\mathrm{Rn}-222)$ that had entered the body primarily via inhalation. The external hazard was chiefly from gamma radiation emitted by the decay of radium (Ra-226) contained in the uranium-bearing ore. Because the uranium materials encountered at the facility were largely physiologically insoluble, the organs of heaviest exposure would be the lungs and lymphatic tissue. However, initially insoluble forms of uranium might be physiologically solubilized by enzymatic systems and transported to the liver, kidney, and bone, causing these sites to be exposed also.

A roster was constructed of all workers ever employed at the Ceramics Plant ( $\mathrm{N}=1551)$, demographic information was collected, and individual work histories were constructed from contemporary earnings records, medical examination records, and security records kept on each employee. The study cohort was restricted to all white males employed at the plant for more than $30 \mathrm{~d}$. Women and nonwhite males were not included because they were few in number. Table 1 defines the selection of the study subjects. Vital status through 31 December 1979 was determined for each worker with the use of the Social Security Administration as the primary source. This source was supplemented by others, including the National Death Index, state death indexes, departments of motor vehicles for each state, employer pension records, and area telephone, city, and Polk directories. Death certificates were obtained through the Department of Energy Death Certificate Retrieval Office at Oak Ridge Associated Universities, and the underlying cause of death was coded, by an experienced nosologist, to the Eighth Revision of the International Classification of Diseases, Adapted for Use in the United States (21).

Mortality in the cohort of white males was compared to two different populations with the use of indirect standardization adjusting on five-year age and calendar-time intervals. The two standards for comparison were (i) the United States (US) white male mortality rates for all causes of death and (ii) the white male mortality rates for all cancer causes of death in the New York counties of Erie and Niagara. These two counties were the ones in which workers at the plant would have resided, and they were chosen as being representative of the regional cancer mortality. Deaths in the study group $(\mathrm{N}=429)$ were not considered to have significantly contributed to the county rates. The standardized mortality ratio (SMR) values were produced by the computer methodology of Monson (13) with the US population as a standard. When the Erie and Niagara County populations were used as the standard, the SMR values were calculated with the use of the site-specific cancer rate tables for 1950-1979 developed by Riggan et al (16) and computer software, developed by one of us (RWM), that calculates SMR values using these rate tables. In the calculation of the SMR values, workers were considered at risk from date of hire until death, loss to follow-up, or the closing date of the study, whichever occurred first. Persons lost to follow up were withdrawn as alive on the date last observed.

Vital status through the end of 1979 was ascertained for $94.3 \%$ of the study group, and verified death certificates were available for $94.6 \%$ of the workers who were reported to be dead (table 2). The analysis included $94.7 \%$ of the maximum number of personyears at risk that would have been used if the persons lost to follow up had survived through 1979.

Table 1. Definition of the cohort used in the analysis of the Linde Air Products Company Ceramics Plant workers.

\begin{tabular}{lr}
\hline & Number \\
\cline { 2 - 2 } Total of workers ever employed & 1551 \\
Exclusions & \\
Females & 306 \\
Nonwhite males & 50 \\
Males of unknown race & 31 \\
Employed less than 30 d & 169 \\
Study population & 995 \\
\hline
\end{tabular}


Table 2. Vital status of the study group through 31 December 1979.

\begin{tabular}{lcc}
\hline Vital status & Number & $\begin{array}{c}\text { Percentage } \\
\text { of total }\end{array}$ \\
\hline Alive & 509 & 51.2 \\
Dead & 429 & 43.1 \\
$\quad$ With certificate & 406 & $94.2^{\mathrm{a}}$ \\
Unknown & 57 & 5.7 \\
\hline Total & 995 & 100.0 \\
\hline
\end{tabular}

a Percentage of deaths.

Because it was necessary to construct the roster from a variety of records that were over 30 years old, its completeness was assessed from an external source, namely the Internal Revenue Service Form 941 Schedule A (IRS-941A), and the procedure outlined by Marsh \& Enterline (10). The roster was compared to the IRS-941A for the last quarter of 1943 and for the first three quarters of 1944. The first year was chosen because it was the year the plant started, and the second was chosen as being representative of a "typical" year of operation in the plant. There was 93-95\% agreement between the two record sources.

A radiation and chemical hazards assessment was done for the Ceramics Plant with the use of operational reports and other records maintained for the Department of Energy at Oak Ridge Associated Universities (6). The information included detailed plant process, chemical use, plant organization, job description, and radiation monitoring data, as well as transcripts of extensive interviews with former plant personnel. Because the present study focuses on the radiation hazards at the plant, details concerning the chemical hazards assessment have not been given in this report, but will be the subject of a subsequent paper.

Four general measurements were found to contain useful information for assessing radiation hazards. They were (i) air Rn-222 and airborne uranium monitoring results [alpha disintegrations per minute $\left.(\mathrm{dpm}) / \mathrm{m}^{3}\right]$, (ii) surface contamination (alpha $\mathrm{dpm} / 100 \mathrm{~cm}^{2}$ ), (iii) urinalysis results (mg $\mathrm{U} / \mathrm{l}$ urine), and (iv) film badge results (mrem per week). The bulk of these measurements were taken during 1947 and 1948 with the exception of the radon measurements taken primarily during 1944 . However, the relative radiological hazards associated with the various jobs did not appear to change appreciably during the period of operation, a characteristic common at uraniumprocessing facilities during the 1940 s.

The first three types of measurement data were used to assess potential for internal ionizing radiation exposure for each job that existed in the plant. Three separate analyses were carried out using each type of data, and the results were combined to assign a given job to one of three exposure groups. Each of these types of data was converted to an estimated lung dose.
A quality factor of 10 for alpha radiation was used to convert exposure to dose equivalent; one working level month was assumed to be equivalent to an absorbed dose of $5 \mathrm{mGy}$; the aerodynamic diameter of respirable uranium was assumed to be 1 micron with a geometric standard of $1.5 ; 120 \mathrm{~d}$ was used as the biological half-time of uranium in the lung; and the average ratio of lung burden to the excretion rate of uranium was taken to be 300 . Jobs entailing duties that would lead to a similar potential annual lung dose were grouped according to a three-tiered semiquantitative categorization. The three groups were jobs that should lead to an annual lung dose of: (i) $<10 \mathrm{mSv}$, (ii) $10-100 \mathrm{mSv}$, and (iii) $>100 \mathrm{mSv}$ with an upper limit of $1000 \mathrm{mSv}$. The current occupational limit for dose to the lung is $150 \mathrm{mSv} /$ year (22).

The limited film badge data were used to evaluate the potential for external exposure to ionizing radiation. Each job in the plant was assigned to one of two categories, namely, jobs with mean weekly film badge results not greater than the minimum detectable level and those greater than the minimum detectable level. This level was probably equivalent to a dose of 0.1 $\mathrm{mSv}$, based on evaluations at similar facilities, although there may be wide variation between facilities (DJ Crawford-Brown and DJ Strom, personal communication).

Because of incomplete monitoring data and a defunct facility, the calculation of individual radiation exposures or the expression of risk factors in units of risk per unit dose equivalent was impossible. However, careful study of detailed operational reports, combined with a considerable amount of monitoring data and personal commentary from knowledgeable, contemporary employees, did permit a reasonable estimation of the dose ranges to workers for the radiological hazards known to be present. As a result, tests were possible for differences in risk between the groups of individuals determined to differ in their range of dose equivalents to the primary organs of interest, namely, the lungs and the lymphatic and whole-body tissues.

Uranium ores having a high Ra-226 content, and therefore emitting gamma radiation during decay, were present in the plant for approximately 18 months. Workers were only allowed to work $2 \mathrm{~h}$ a day with these ores to minimize their chance of exposure to high levels of gamma radiation. From the limited film badge data available for the last 24 months of operation, the highest cumulative dose for a worker during this period was about $20 \mathrm{mSv}$. We believe that the external radiation doses rarely, if ever, exceeded $20 \mathrm{mSv} /$ year. The current occupational whole-body dose limit for external ionizing radiation is $50 \mathrm{mSv}$ per calendar year (22). Therefore, throughout the analysis, workers were categorized only according to estimated internal dose categories since the internal exposure was higher than the external exposure and there was a high correlation between potential for internal and external exposure. 
The ordinal scheme used to assign internal radiation exposure made it difficult to determine cumulative internal radiation exposure for each worker. Therefore, analysis of mortality by cumulative internal radiation exposure was not done. Neither was analysis by length of employment since internal radiation exposure is not necessarily reflected by length of employment. However, it was possible to assign a lower limit of cumulative internal radiation exposure to the subcohort of workers who spent most of their work time in jobs with the highest internal radiation exposure (ie, jobs that would lead to lung doses of $>100 \mathrm{mSv} /$ year) and who worked in these jobs for more than one year. Therefore, this subcohort was chosen to evaluate the effect of long-term occupational exposure from internal radiation. Since this subcohort of workers received a lung dose that approached or exceeded the current occupational lung dose limit of $150 \mathrm{mSv} /$ year (22), the results of this analysis also allow an evaluation of the safety of this limit. The SMR analysis of this subcohort was done with the US white male population as the standard.

\section{Results}

The distributions of age at first employment, year of first employment, and length of employment are given in table 3. On the average a worker was first employed in the first quarter of 1944 at the age of 33.8 years and remained employed at the plant for 1.4 years.

Table 4 gives the population distribution of the internal lung dose ranges by the dose level in which a worker spent most of his time. Of the 377 workers who spent most of their work time in the highest dose group and the 212 who spent most of their time in the lowest dose group, 149 and 95, respectively, worked at this exposure level for more than one year.

The SMR values determined with the US population as the standard are given in table 5 for those causes of death for which more than five deaths were observed. Statistically significant excesses were found for all causes of death combined, all diseases of the circulatory system, arteriosclerotic heart disease, all respiratory disease, all pneumonia, and cancer of the larynx. No statistically significant deficits were observed. The observed number of lymphatic and lung cancers were essentially as expected. Of the six lymphatic cancer deaths, two were from reticulum cell sarcoma and one each from Hodgkin's disease, multiple myeloma, acute myeloid leukemia, and chronic myeloid leukemia. The SMR was not statistically different from the one for malignant or nonmalignant diseases of the bone, liver or genitourinary system. When the Erie and Niagara County rates were used as the standard, the SMR values for each site-specific cancer were slightly lower than those calculated with the US standard, and the SMR for cancer of the larynx was still statistically significant. Table 6 gives the SMR values for selected cancer causes with the county populations as the standard.
Fifty-nine deaths occurred among the subcohort of 149 workers who were exposed for more than a year to internal radiation at levels that would lead to a lung dose of $>100 \mathrm{mSv} /$ year. Although the number of deaths was small, the mortality pattern seen among this subcohort is generally the same as that observed for the entire study group. For the subcohort the SMR for all causes combined was 116 [95\% confidence interval (95\% CI) 088-150]. For all malignant neoplasms combined 11 deaths were observed giving an SMR of 108 (95\% CI 054-194). No statistically significant deviations from the expected values were observed for any specific cause of death. A more appropriate comparison of mortality for the high internal radiation exposure group would be that group of workers who worked for a comparable time but had minimal potential for internal radiation exposure. However, there was a five-year discrepancy in the average age at first hire between these two groups, and therefore comparisons of indirectly standardized SMR values were questionable since the younger cohort is now reaching the age at which mortality rates increase rapidly.

Because the healthy worker effect was not seen in this study population, SMR analyses were performed using earlier cut-off dates of follow-up (ie, 31 Decem-

Table 3. Frequency distributions for selected variables among the study group.

\begin{tabular}{lrr}
\hline Variable & Number & Percentage \\
\hline Age at first empioyment (years) & & \\
$16-25$ & 289 & 29.0 \\
$26-35$ & 346 & 34.8 \\
$36-45$ & 203 & 20.4 \\
$46-55$ & 145 & 14.6 \\
$\geq 56$ & 12 & 1.2 \\
Year of first employment & & \\
1943 & 330 & 33.2 \\
1944 & 288 & 29.0 \\
1945 & 285 & 28.6 \\
1946 & 73 & 7.3 \\
1947 & 14 & 1.4 \\
1948 & 5 & 0.5 \\
Length of employment (years) & & \\
$<1$ & & \\
$1-1.9$ & 555 & 55.8 \\
$2-2.9$ & 144 & 14.5 \\
$3-3.9$ & 114 & 11.5 \\
$4-4.9$ & 100 & 10.0 \\
$\geq 5$ & 25 & 2.5 \\
& 57 & 5.7 \\
\hline
\end{tabular}

Table 4. Distribution of annual dose of internal radiation to the lung by level in which most of the workers' employment time was spent.

\begin{tabular}{lcc}
\hline Potential lung dose (mSvlyear) & Number & Percentage \\
\hline Unknown & 4 & 0.4 \\
$<10$ & 212 & 21.3 \\
$10-100$ & 402 & 40.4 \\
$>100$ & 377 & 37.9 \\
\hline Total & 995 & 100.0 \\
\hline
\end{tabular}


Table 5. Numbers of observed and expected deaths for selected causes among the study group ${ }^{\mathrm{a}}(\mathrm{N}=995)$ with the United States white male population as the standard.

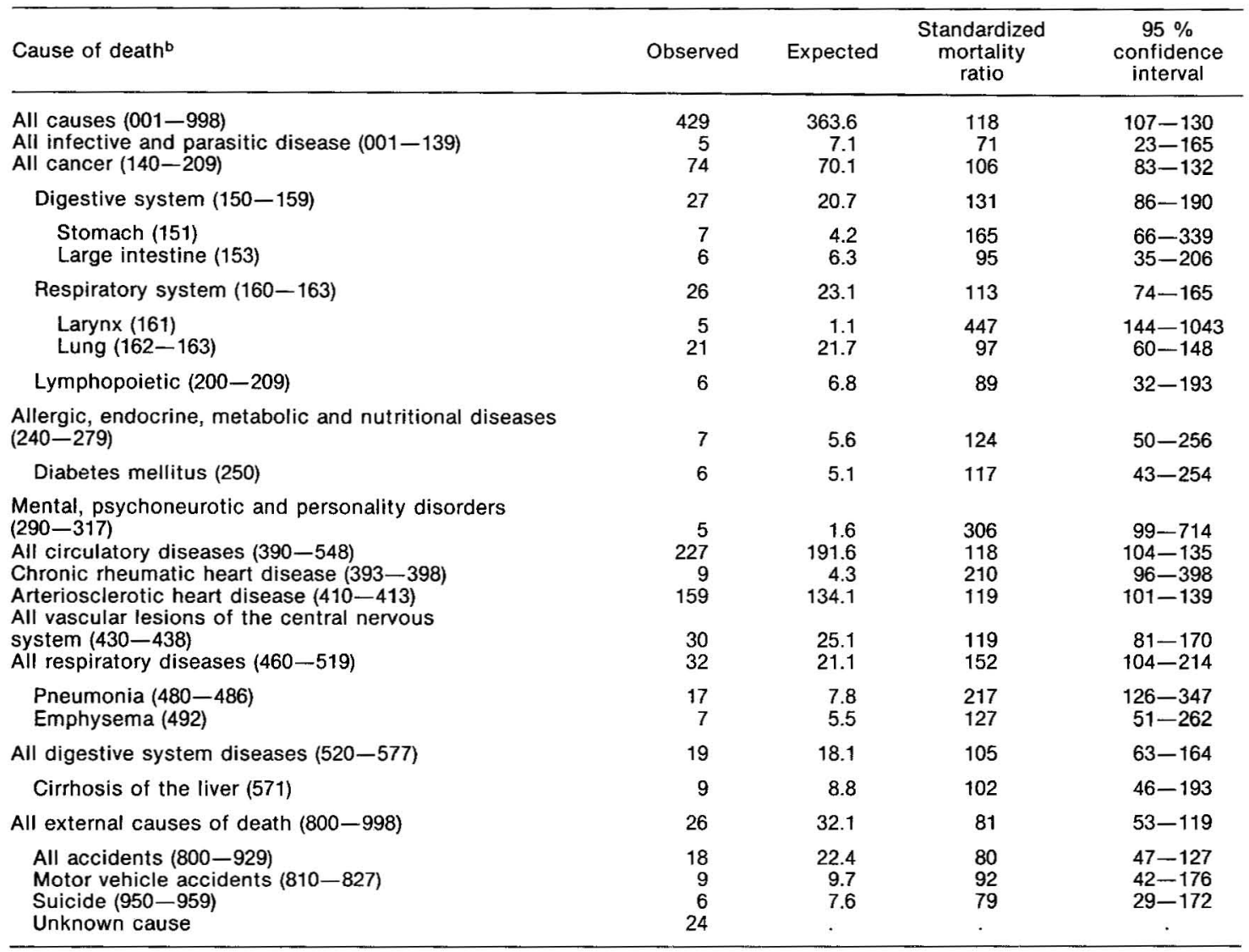

a Person-years 27740.2 , average age at death 61.3 years.

b The code of the Eighth Revision of the International Classification of Diseases, Adapted for Use in the United States (21) in parentheses.

Table 6. Number of observed $(O)$ and expected $(E)$ deaths for selected cancer causes among the study group $(N=995)$ with the white male population of two counties in New York state (Erie and Niagara) as the standard. (SMR = standardized mortality ratio, $95 \% \mathrm{Cl}=95 \%$ confidence interval)

\begin{tabular}{lrrrr}
\hline Cause of death & O & E & SMR & $95 \% \mathrm{CI}$ \\
\hline All cancer & 74 & 77.8 & 95 & $79-126$ \\
Digestive system & 27 & 24.6 & 110 & $72-160$ \\
$\quad$ Stomach & 7 & 4.9 & 144 & $58-297$ \\
$\quad$ Large intestine & 6 & 7.7 & 78 & $28-168$ \\
Respiratory system & 26 & 26.0 & 100 & $65-146$ \\
$\quad$ Larynx & 5 & 1.4 & 357 & $121-873$ \\
$\quad$ Lung & 21 & 24.5 & 85 & $60-147$ \\
Lymphopoietic & 6 & 6.5 & 92 & $34-198$ \\
\hline
\end{tabular}

ber 1950, 31 December 1960, 31 December 1970) in order to determine if this effect was ever present in the population. Table 7 gives the results of the SMR analyses for selected causes of death for the three different cut-off dates. A statistically significant deficit of deaths was never observed for any cause in any of the analyses. Mortality from circulatory diseases was never less than expected, and it was largely responsible for the all-causes SMR being higher than what is usually observed in an occupational population.

\section{Discussion}

Because of the potential for exposure to ionizing radiation from uranium, certain mortality outcomes are of special interest, namely, cancers that have been strongly associated with radiation exposure (ie, some leukemias, cancers of the bone, lung and thyroid, and multiple myeloma), and cancers and diseases of organ systems that have potential for exposure due to the ingestion or inhalation of uranium (ie, those of the respiratory, digestive, and genitourinary systems). Among these, only deaths from nonmalignant diseases of the respiratory system, pneumonia, and laryngeal cancer (a cancer of the respiratory tract) showed statistically significant increases. The statistically significantly increased SMR observed for diseases of the respiratory 
Table 7. Number of observed and expected deaths from selected causes for three different cut-off dates for follow-up of the study group $(\mathrm{N}=995)$ with the United States white male population as the standard. (SMR = standardized mortality ratio)

\begin{tabular}{|c|c|c|c|c|c|c|c|c|c|}
\hline \multirow{3}{*}{ Cause of death } & \multicolumn{9}{|c|}{ Follow-upa } \\
\hline & \multicolumn{3}{|c|}{31 December 1950} & \multicolumn{3}{|c|}{31 December 1960} & \multicolumn{3}{|c|}{31 December 1970} \\
\hline & Observed & Expected & SMR & Observed & Expected & SMR & Observed & Expected & SMR \\
\hline $\begin{array}{l}\text { All causes } \\
\text { All cancers } \\
\text { All circulatory diseases }\end{array}$ & $\begin{array}{r}29 \\
5 \\
11\end{array}$ & $\begin{array}{r}30.7 \\
3.9 \\
11.0\end{array}$ & $\begin{array}{r}95 \\
127 \\
100\end{array}$ & $\begin{array}{r}124 \\
17 \\
66\end{array}$ & $\begin{array}{r}102.6 \\
16.3 \\
47.4\end{array}$ & $\begin{array}{l}121 \\
104 \\
139^{\star}\end{array}$ & $\begin{array}{r}270 \\
46 \\
140\end{array}$ & $\begin{array}{r}224.4 \\
39.8 \\
114.5\end{array}$ & $\begin{array}{l}120^{\star} \\
116 \\
122^{\star}\end{array}$ \\
\hline $\begin{array}{l}\text { Chronic rheumatic } \\
\text { heart diseases } \\
\text { Arteriosclerotic }\end{array}$ & 0 & 0.7 & - & 5 & 2.1 & 235 & 8 & 3.3 & $241^{\star}$ \\
\hline heart disease & 9 & 5.4 & 168 & 47 & 30.0 & $157^{*}$ & 102 & 77.8 & $131^{*}$ \\
\hline All respiratory diseases & 3 & 1.3 & 238 & 8 & 4.3 & 185 & 17 & 11.4 & 149 \\
\hline Pneumonia & 3 & 0.8 & 388 & 6 & 2.0 & 297 & 11 & 4.6 & $242^{*}$ \\
\hline $\begin{array}{l}\text { Person-years } \\
\text { Average age (years) at death }\end{array}$ & & $\begin{array}{r}5996.5 \\
47.2\end{array}$ & & & $\begin{array}{r}14788.3 \\
52.6\end{array}$ & & & $\begin{array}{r}22384.8 \\
57.3\end{array}$ & \\
\hline
\end{tabular}

a These groups are inclusive. For example, the 124 deaths that occurred by the end of the 1960 are included in the 270 deaths that occurred by the end of 1970 .

* $P<0.05$.

system was primarily attributable to a statistically significant increase in deaths from pneumonia. The SMR for all cancers of the respiratory system was not statistically significant. The statistically significant excess of laryngeal cancer deaths contributed the largest component to this SMR. Since the Buffalo area has been identified as an area of increased cancer mortality rates compared to the United States as a whole (11), using the Erie and Niagara County rates increased the expected numbers, reducing the SMR for all site-specific cancers, although the SMR for laryngeal cancer remained statistically significantly increased.

Cancer of the larynx is known to be related to both tobacco and alcohol use. Information on these factors was not recorded in contemporary plant records. It was available for the period just prior to death for one of the five men who died from laryngeal cancer. The medical record reported heavy use of tobacco and alcohol by this cohort member. The fact that the SMR for lung cancer was equal to 100 could be an indication that tobacco usage in this cohort was about the same as that of the US population. Similarly, cirrhosis of the liver could be an indicator of alcohol usage in the cohort. Although the SMR for cirrhosis of the liver was 100 , all five deaths due to mental disorders also had effects of chronic alcoholism listed on the death certificate. Therefore, alcohol usage among the workers could have been elevated and may account for some portion of the increase in deaths due to laryngeal cancer.

The median age of occurrence of laryngeal cancer is in the seventh or eighth decade for US white males (18). All of the observed deaths due to this disease in the Ceramics Plant population occurred in the sixth decade, except one, which occurred in the eighth. The age at first hire ranged from 27 to 55 years, and the period of time between age of first hire and death ranged from 14 to 25 years. Three of the five worked at the beginning of the uranium processing operations when exposures to internal radiation, sulfuric acid, and silicon dioxide were likely to be at the highest levels in the plant. Although nickel was present in the plant and in some forms has been linked to cancer of the larynx (5), none of these men was exposed to nickel at this facility. With the small number of deaths, it would be difficult to determine whether any of the exposures considered was causally related to laryngeal cancer.

The SMR for pneumonia has steadily decreased from 388 in 1950 to 217 in 1979. Three of the 17 deaths from pneumonia occurred before 1950. Pulmonary tuberculosis was mentioned as a contributory cause on two of the three death certificates. Among the 14 pneumonia deaths that occurred after 1950 , only one listed tuberculosis as a contributory cause. While exposures to vanadium, fluoride compounds, nitric acid, and sulfuric acid were possible at the Ceramics Plant and have been associated with increased risk of pneumonia (14), there was no evidence to suggest that exposures to these substances were excessive among the pneumonia decedents when compared to the entire study cohort or to all the decedents. The average level of exposure to internal ionizing radiation was less than that for the entire study group. For those who died of pneumonia, the average age at first hire was $\mathbf{4 5 . 2}$ years, which was substantially higher than that for all workers combined (33.4 years) and for workers who had died (39.6 years).

It is unusual to find the all-causes SMR elevated in an occupational cohort. Because of the healthy worker effect the SMR for all causes and, particularly, circulatory diseases is usually less than 100 in worker populations although the effect tends to disappear as a population ages. The long follow-up period $(\geq 30$ years) may have nullified this effect. However, even when earlier cut-off dates for follow-up were used, the healthy worker effect was absent in this cohort. The SMR for all circulatory diseases was never less than 
unity. Review of the work histories provided no evidence to suggest that radiation and chemical exposures among those who died of circulatory diseases were different from the cohort as a whole. Because the war emergency caused a marked decrease in the available labor force throughout the country, individuals whose physical status would not meet employment requirements in peaceful times were accepted for employment. Potential employees were refused only for "obvious kidney pathology, extreme cardiovascular disease, and various pulmonary conditions, particularly chronic bronchial asthma"' (7). Examination of the physicals for the 158 men who died of arteriosclerotic heart disease identified 43 who were hypertensive [ie, diastolic blood pressure $>95 \mathrm{~mm} \mathrm{Hg}(>12.7 \mathrm{kPa})]$, or had a history of scarlet or rheumatic fever, or heart disease. An additional 11 men who had no recorded history of any of these conditions were rejected from military service for unknown medical reasions. Among the nine men who died of rheumatic heart disease, six had a history of rheumatic or scarlet fever or had a heart abnormality noted on their preemployment physical.

The only outcomes of special interest that were statistically different from expected were all nonmalignant respiratory diseases and site-specific diseases of the respiratory system, namely, laryngeal cancer and pneumonia. No association was found between these outcomes and long-term occupational exposure internally to high levels of ionizing radiation. The lack of any excess mortality from lung cancers is contrary to what has been seen in studies of other uranium workers, particularly of uranium miners. Among workers at a uranium-processing plant in operation during the same period as the Ceramics Plant, Polednak \& Frome (15) found a nonstatistically significant increase of lung cancer which was not observed in the present investigation. However, unlike the Ceramics Plant cohort, the SMR values for all causes and all cancers were less than 100 . There is no clear explanation for the difference in the SMR values. The age at first hire was similar for both groups of workers. In both cases, the source of the worker population would be expected to include a larger portion of men who were unfit for military service or were beyond draft age. Based on historic air monitoring records, the internal radiation exposure levels were probably similar at the two plants, as were many of the potential chemical exposures. Further analysis of mortality among the Ceramics Plant population will consider the preemployment health status and personal characteristics of the workers, as well as other potential chemical exposures known to have existed at the plant.

\section{Acknowledgments}

The authors thank Dr S Austin, Mr N Bolton, Ms S Hart, Mr V Hayes, Ms C Favata, and Ms J Burris of the Union Carbide Corporation, and Dr CC Lushbaugh, Ms K Gissel, Ms J McClanahan, Ms C Murphy, and the staff of the Death Certificate Retrieval Office of Oak Ridge Associated Universities for their assistance in this study. We would also like to thank the former employees of the Ceramics Plant, who provided valuable first-hand information concerning the operations at the facility.

This work was undertaken as part of contract no DE-AC05-760R00033 from the US Department of Energy, Office of Energy. Research. Part of the data was collected under a previous contract from the US Atomic Energy Commission, and later from the US Energy Research and Development Administration (no E11-1-3438) under the direction of Dr TF Mancuso, University of Pittsburgh.

\section{References}

1. Boice JD, Land CE, Shore RE, Norman JE, Tokanaga $M$. Risk of breast cancer following low-dose exposure. Radiology 131 (1979) 589-597.

2. Committee on the Biological Effects of Ionizing Radiation. The effects on populations of exposure to low levels of ionizing radiation. National Academy Press, Washington, DC 1980.

3. Cookfair DL. Lung cancer among workers at a uranium processing plant. In: Health Physics Society. Epidemiology applied to health physics: Proceedings of the sixteenth midyear topical symposium, Albuquerque, NM, January 10-14, 1983. National Technical Information Service, Springfield, VA 1984, pp 398-406. (US Department of Energy Report CONF-830101).

4. Cragle DL, Hollis DR, Newport TH, Shy CM. A retrospective cohort mortality study among workers occupationally exposed to metallic nickel powder at the Oak Ridge Gaseous Diffusion Plant. In: Sunderman FW, ed. Nickel in the human environment. Oxford University Press, New York, NY 1984, pp 57-63. (IARC scientific publication no 53).

5. Enterline PE, Marsh GM. Mortality among workers in a nickel refinery and alloy manufacturing plant in West Virginia. J Natl Cancer Inst 68 (1982) 925-933.

6. Hickey JLS, Crawford-Brown D, Tankersley WG. Occupational exposures of workers to chemicals and radiation during uranium processing at the Linde Ceramics Plant, 1943-1949. Oak Ridge Associated Universities, Oak Ridge, TN 1985. (ORAU technical report no 243).

7. Howland JW. Studies on human exposure to uranium compounds. In: Voegtlin C, Hodge H, ed. Pharmacology and toxicology of uranium compounds. McGrawHill Book Company Inc, New York, NY 1949, pp 993-1017.

8. Kato H, Schull WJ. Studies of mortality in A-bomb survivors; 7. Mortality, 1950-1978: Part I Cancer mortality. Radiat Res 90 (1982) 395-432.

9. Lundin FE, Wagoner JK, Archer VE. Radon daughter exposure and respiratory cancer: Quantitative and temporal aspects. National Technical Information Service, Springfield, VA 1971. (NIOSH/NIEHS joint monograph no 1).

10. Marsh GM, Enterline PE. A method for verifying the completeness of cohorts used in occupational mortality studies. J Occup Med 21 (1979) 665-670.

11. Mason TJ, McKay FW, Hoover R, Blot WJ, Fraumeni JF. Atlas of cancer mortality for US counties 1950-1969. US Government Printing Office, Washington, DC 1976. (DHEW publication no (NIH) 76-1204). 
12. Matanoski GM, Sartwell P, Elliot E, Tonascia J, Sternberg A. Cancer risks in radiologists and radiation workers. In: Boice JD, Fraumeni JF, ed. Radiation carcinogenesis: Epidemiology and biological significance. Raven Press, New York, NY 1984, pp 83-96.

13. Monson RR. Analysis of relative survival and proportional mortality. Computers Biomed Res 7 (1974) 325-332.

14. Plunkett EP. Occupational diseases: A syllabus of signs and symptoms. Barrett Book Company, Stamford, CT 1977.

15. Polednak AP, Frome EL. Mortality among men employed between 1943 and 1947 at a uranium-processing plant. J Occup Med 23 (1981) 169-179.

16. Riggan WB, Van Bruggen J, Acquavella JF, Beaubier $J$, Mason TJ. US cancer mortality rates and trends, 1950-1979. US Government Printing Office, Washington, DC 1983. (National Cancer Institute and US Environmental Protection Agency publication no EPA-600/1 -83-015a).

17. Rowland RE, Stehney AF, Lucas HF. Dose-response relationships for female radium dial workers. Radiat Res 76 (1978) 368一 383 .

18. Schottenfeld D, Fraumeni JF. Cancer epidemiology and prevention. WB Saunders Company, Philadelphia, PA 1982.

19. Smith PG. Late effects of $x$-ray treatment of ankylosing spondylitis. In: Boice JD, Fraumeni JF, ed. Radiation carcinogenesis: Epidemiology and biological signif- icance. Raven Press, New York, NY 1984, pp 107-118.

20. Soskolne CL, Zeighami EA, Hanis NM, Kupper LL, Hermann N, Amsel J, Mausner JS, Stellman JS. Laryngeal cancer and occupational exposure to sulfuric acid. Am J Epidemiol 120 (1984) 358-369.

21. United States Department of Health, Education and Welfare. Eighth revision of the international classification of diseases, adapted for use in the United States. US Government Printing Office, Washington, DC 1968. (Public Health Service publication no 1693).

22. US National Council on Radiation Protection and Measurements. Basic radiation protection criteria. Washing ton, DC 1968. (NCRP report 39).

23. Wagoner JK, Archer VE, Carroll BE, Holaday DA, Lawrence PA. Cancer mortality patterns among US uranium miners and millers, 1950 through 1962 . J Natl Cancer Inst 32 (1964) 787-801.

24. Waxweiler RJ, Archer VE, Roscoe RJ, Watanabe A, Thun MJ. Mortality patterns among a retrospective cohort of uranium mill workers. In: Health Physics Society. Epidemiology applied to health physics: Proceedings of the sixteenth midyear topical symposium, $\mathrm{Al}$ buquerque, NM, January 10-14, 1983. National Technical Information Service, Springfield, VA 1984 pp 428-435. (US Department of Energy report CONF-830101).

Received for publication: 26 June 1986 